\title{
Microsatellite polymorphism in Tunisian pomegranates (Punica granatum L.): Cultivar genotyping and identification
}

\author{
Jbir Rania ${ }^{\mathrm{a}}$, Zehdi Salwa ${ }^{\mathrm{a}}$, Hasnaoui Najib ${ }^{\mathrm{a}}$, Ben Dhiaf Amal ${ }^{\mathrm{a}}$, Mars Messaoud ${ }^{\mathrm{b}}$, \\ Salhi Hannachi Amel ${ }^{\text {a,* }}$ \\ ${ }^{a}$ Laboratory of Molecular Genetics, Immunology E Biotechnology, Faculty of Sciences, University El Manar, Campus Universitaire, 2092 El Manar, Tunis, Tunisia \\ ${ }^{\mathrm{b}}$ U.R. Agrobiodiversity, High Agronomic Institute, 4042 Chott-Mariem, University of Sousse, Tunisia
}

\section{A R T I C L E I N F O}

\section{Article history:}

Received 4 July 2011

Accepted 6 April 2012

Available online $\mathrm{xxx}$

\section{Keywords:}

Punica granatum

Molecular polymorphism

SSR

Cultivar identification key

\begin{abstract}
A B S T R A C T
Specific microsatellites (SSRs) markers were used to characterize a set of 32 Tunisian pomegranate (Punica granatum L.) cultivars. Using 13 SSR primers, a total of 40 alleles and 46 genotypes have been identified. As a result, data proved that a high level of polymorphism characterizes the Tunisian pomegranate germplasm at the DNA level. The derived Neighbour-joining (NJ) dendrogram constructed using DAS genetic distances exhibited a genetic diversity structured independently from the geographical origin of cultivars and their denomination. This result suggested that a common genetic basis may characterize Tunisian pomegranate cultivars despite their phenotypic divergences. Furthermore, based on the multilocus genotypes a cultivar's identification key has been established and permitted to unambiguously differentiate between varieties. The obtained results are discussed in term of establishment and management of a national collection of pomegranate varieties, conformity checks, identification of homonyms and synonyms, and screening of the local resources. Furthermore, this microsatellite-based key is a first step towards a marker-assisted identification pomegranate database.
\end{abstract}

(c) 2012 Elsevier Ltd. All rights reserved.

\section{Introduction}

The pomegranate, Punica granatum $\mathrm{L} .(2 \mathrm{n}=16)$, included in the family of Punicaceae, is one of the oldest known fruit trees (Guarino et al., 1990; Melgarejo Moreno and Martínez Valero, 1992). Pomegranates have widely spread, since Roman period, in different Mediterranean countries where a large number of cultivars have been identified (Ozguven, 1996; Mars, 1996, 2001; Mars and Marrakchi, 1998). This area was, therefore, considered as secondary centre of diversification of this crop. Since it is a monoecious and preferably allogamous, species develop male and perfect flowers (Mars and Marrakchi, 2004). The pomegranate has been described variously as self-pollinated, self and cross-pollinated, highly cross-pollinated or often crosspollinated (Karale et al., 1993). Pomegranate cultivars, selected traditionally by farmers, were maintained through vegetative propagation and in course of time, have received names referring mainly to geographical origin and/or fruit colour (Mars and Marrakchi, 2004). Genetic erosion due to biotic and abiotic stresses was also reported and concerned many cultivars that are well adapted to local and regional conditions (Levin, 1995; Mars et al., 1994; Mars and Marrakchi, 1998). Establishment of genetic resources conservation strategies has, therefore, become imperative in order to preserve local pomegranate germplasm. In Tunisia, prospections were conducted in all pomegranate growing areas and permitted the collection of numerous cultivars (Mars and Marrakchi, 1998; Mars, 2001). Identification and characterization of the collected genotypes constitutes an attractive

\footnotetext{
* Corresponding author. Tel.: +216 718726 00; fax: +216 70860432 .

E-mail address: Amel.SalhiHannachi@fsb.rnu.tn (S.H. Amel).
} 
task to examine level and distribution of genetic diversity in this crop. For this purpose, studies have reported the use of morpho-phenological and pomological traits to characterize pomegranate cultivars (Mars and Marrakchi, 1999, 2004). As suggested by Mars and Marrakchi (1999) and Mars and Marrakchi (2004) a high phenotypic variability characterize local resources regarding their leaf, flower and fruit characteristics. Accessions are often classified as sweet, sweet-sour and sour, early, mid season and late, juicy and table fruit, soft-seeded and hard-seeded or major and minor. Also, chemical and biochemical parameters have been used for Tunisian pomegranates and permitted to discriminate cultivars according to fruit constituents (Ben Nasr et al., 1996; Hasnaoui et al., 2010). However, these analyses are less rewarding since they were based on parameters limited in number and/or highly influenced by the environmental conditions. To overcome such inconvenience, AFLP markers were developed and successfully used to characterize cultivars and to establish genetic relationships between varieties (Jbir et al., 2008, 2009). Recently, in order to provide necessary additional information on pomegranate genetic resources, SSR (Simple Sequence Repeats or microsatellites) primers were developed and designed for P. granatum L. (Hasnaoui et al., 2010; Pirseyedi et al., 2010; Ebrahimi et al., 2010). In fact, SSRs are of several benefits over other available DNA-based methods. They are highly frequent, uniformly dispersed over genomes, easily transferable, of co-dominance inheritance and able to generate high levels of polymorphism. Here, microsatellite markers were used to examine the level and structure of genetic diversity and develop an identification key for this fruit crop.

\section{Materials and methods}

\subsection{Plant material}

Thirty two Tunisian pomegranate cultivars maintained in ex situ collection were used in this study. Table 1 illustrates the denomination and origin of the studied cultivars. According to their geographical origin, considered cultivars were ranged into two groups namely: South and North (Table 1). The plant material consisted of young leaves sampled from adult trees. The sampled plant material was freshly used or frozen at $-80{ }^{\circ} \mathrm{C}$ for nucleic acids purification.

\subsection{DNA isolation}

Total cellular DNA was purified from young leaves as described by Dellaporta et al. (1984). DNA concentration was estimated by analytic agarose gel electrophoresis according to Sambrook et al. (1989).

Table 1

Denomination and origin of the 32 studied Tunisian pomegranate cultivars.

\begin{tabular}{|c|c|c|c|}
\hline Label & Cultivar & Geographical origin & Group \\
\hline TN9-2 & Tounsi 9 & Sedaghiane (Jerba) & South \\
\hline JR2 & Jerbi 2 & Sedaghiane (Jerba) & \\
\hline TN10 & Tounsi 10 & Srandi (Jerba) & \\
\hline TN17 & Tounsi 17 & El May (Jerba) & \\
\hline $\mathrm{CH} 17$ & Chelfi 17 & Srandi (Jerba) & \\
\hline BY1 & Beyounsi 1 & Sedaghiane (Jerba) & \\
\hline $\mathrm{CH} 7$ & Chelfi 7 & Srandi (Jerba) & \\
\hline $\mathrm{CH} 8-3$ & Chelfi 8-3 & Sedaghiane (Jerba) & \\
\hline $\mathrm{CH} 9$ & Chelfi 9 & Sedaghiane (Jerba) & \\
\hline $\mathrm{CH} 15$ & Chelfi 15 & Sedaghiane (Jerba) & \\
\hline $\mathrm{CH} 16$ & Chelfi 16 & El May (Jerba) & \\
\hline GB11 & Gabsi 11 & Sedaghiane (jerba) & \\
\hline ZH11 & Zehri 11 & Sedaghiane (jerba) & \\
\hline RF1 & Rafrafi 1 & Zerkine (Mareth) & \\
\hline JB8 & Jebali 8 & Sbikha & \\
\hline $\mathrm{CH} 13$ & Chelfi & Sbikha & \\
\hline $\mathrm{ZH} 4$ & Zehri 4 & Sidi Bou Ali & \\
\hline $\mathrm{CH} 4$ & Chelfi 4 & Sidi Bou Ali & \\
\hline ZH5 & Zehri 5 & Beni Khalled & \\
\hline JB5 & Jebali 5 & Mehrine & \\
\hline JB2 & Jebali 2 & El Alia & \\
\hline JB4 & Jebali 4 & El Alia & \\
\hline CHT1 & Chetoui & El Alia & \\
\hline GB6 & Gabsi 6 & Ghar El Meleh & \\
\hline NB1 & Nebli & Esslouguia (Testour) & \\
\hline $\mathrm{CH} 3$ & Chelfi 3 & Testour & \\
\hline TN2 & Tounsi 2 & Testour & \\
\hline FP2 & Double Flowers Variegated & Tunis & \\
\hline FP1 & Double Flowers Red & Tunis & \\
\hline
\end{tabular}




\subsection{Primers and SSR assays}

A total of fifteen specific primer combinations designed by Hasnaoui et al. (2010) were tested for their power and ability to generate microsatellite markers. Only 13 combinations generated reproducible patterns. Additional information about primers is reported in Table 2.

PCR assays were performed in a reaction mixture of $25 \mu \mathrm{l}$ including 20-30 ng of total cellular DNA (1 $\mu$ l, 10 pM of each primer, $100 \mu \mathrm{M}$ of each dNTP, $1 \mathrm{U}$ of Go Taq DNA polymerase (Promega, Madison WI USA), 1x Colourless GoTaq Flexi Buffer (Promega), and $2.5 \mathrm{mM} \mathrm{MgCl}_{2}$, qsp $25 \mu \mathrm{l} \mathrm{H} \mathrm{H}_{2}$ ).

Amplifications were performed in a TECHNE Thermocycler (TC-512) programmed to execute the following cycling: a denaturation step of $4 \mathrm{~min}$ at $95^{\circ} \mathrm{C}$ followed by 35 cycles of $30 \mathrm{~s}$ at $94{ }^{\circ} \mathrm{C}, 40 \mathrm{~s}$ at $50{ }^{\circ} \mathrm{C}$ and $30 \mathrm{~s}$ at $72{ }^{\circ} \mathrm{C}$, and a final extension step at $72{ }^{\circ} \mathrm{C}$ for $10 \mathrm{~min}$. A negative control (reaction mixture without any DNA), was also included in each experiment. Amplification products were firstly checked on 2\% agarose gels and SSR banding profiles were resolved on non denaturing polyacrylamide gels (10\%) stained by ethidium bromide according to Sambrook et al. (1989).

\subsection{Data analysis}

For each of the defined groups of cultivars, genetic diversity was estimated by mean number of alleles, allele frequencies, observed $\left(H_{\text {obs }}\right)$ and expected $\left(H_{\text {exp }}\right)$ heterozygosity according to Nei (1978) formula. In addition, total genetic diversity $\left(H_{t}\right)$, mean genetic diversity within group $\left(H_{S}\right)$ was also estimated. All analyses were performed by computing data with the

Table 2

Alleles and genotypes revealed by microsatellite markers in Tunisian pomegranate cultivars. Expected $\left(H_{\mathrm{exp}}\right)$ and observed $\left(H_{\mathrm{obs}}\right)$ heterozygosity per locus were indicated.

\begin{tabular}{|c|c|c|c|c|c|c|c|}
\hline \multirow[t]{2}{*}{ Locus } & \multicolumn{3}{|l|}{ Alleles } & \multirow[t]{2}{*}{ Genotypes } & \multirow[t]{2}{*}{$H_{\text {exp }}$} & \multirow[t]{2}{*}{$H_{\mathrm{obs}}$} & \multirow[t]{2}{*}{$P$-value } \\
\hline & Number & Length & Frequency & & & & \\
\hline \multirow[t]{3}{*}{ Pom004 } & 3 & 112 & 0.03 & 3 & 0.20 & 0.06 & $0.0500^{* *}$ \\
\hline & & 116 & 0.87 & & & & \\
\hline & & 120 & 0.09 & & & & \\
\hline \multirow[t]{5}{*}{ Pom006 } & 5 & 153 & 0.11 & 7 & 0.49 & 0.26 & $0.0300^{* *}$ \\
\hline & & 155 & 0.59 & & & & \\
\hline & & 159 & 0.08 & & & & \\
\hline & & 165 & 0.14 & & & & \\
\hline & & 171 & 0.08 & & & & \\
\hline \multirow[t]{3}{*}{ Pom010 } & 3 & 234 & 0.34 & 3 & 0.61 & 0.85 & $0.0060^{* *}$ \\
\hline & & 236 & 0.25 & & & & \\
\hline & & 248 & 0.41 & & & & \\
\hline \multirow[t]{4}{*}{ Pom013 } & 4 & 156 & 0.02 & 5 & 0.56 & 0.25 & $0.0400^{* *}$ \\
\hline & & 158 & 0.17 & & & & \\
\hline & & 162 & 0.67 & & & & \\
\hline & & 164 & 0.14 & & & & \\
\hline \multirow[t]{4}{*}{ Pom014 } & 4 & 192 & 0.06 & 4 & 0.33 & 0.11 & $0.0300^{* *}$ \\
\hline & & 198 & 0.19 & & & & \\
\hline & & 200 & 0.73 & & & & \\
\hline & & 205 & 0.02 & & & & \\
\hline \multirow[t]{6}{*}{ Pom021 } & 6 & 190 & 0.39 & 5 & 0.61 & 0.89 & 0.5900 \\
\hline & & 195 & 0.06 & & & & \\
\hline & & 198 & 0.02 & & & & \\
\hline & & 200 & 0.47 & & & & \\
\hline & & 205 & 0.05 & & & & \\
\hline & & 210 & 0.02 & & & & \\
\hline \multirow[t]{3}{*}{ Pom024 } & 3 & 225 & 0.16 & 5 & 0.46 & 0.53 & $0.0300^{* *}$ \\
\hline & & 230 & 0.47 & & & & \\
\hline & & 240 & 0.37 & & & & \\
\hline \multirow[t]{2}{*}{ Pom039 } & 2 & 140 & 0.95 & 2 & 0.04 & 0.05 & 0.3400 \\
\hline & & 146 & 0.05 & & & & \\
\hline \multirow[t]{2}{*}{ Pom045 } & 2 & 150 & 0.78 & 3 & 0.35 & 0.25 & $0.0500^{* *}$ \\
\hline & & 158 & 0.22 & & & & \\
\hline \multirow[t]{2}{*}{ Pom046 } & 2 & 215 & 0.81 & 3 & 0.22 & 0.21 & $0.0500^{* *}$ \\
\hline & & 240 & 0.19 & & & & \\
\hline \multirow[t]{3}{*}{ Pom047 } & 3 & 205 & 0.52 & 3 & 0.51 & 0.97 & 0.2000 \\
\hline & & 210 & 0.47 & & & & \\
\hline & & 213 & 0.02 & & & & \\
\hline Pom053 & 1 & 205 & 1 & 1 & 0.00 & 0.00 & - \\
\hline \multirow[t]{2}{*}{ Pom055 } & 2 & 245 & 0.25 & 3 & 0.33 & 0.28 & 0.5000 \\
\hline & & 250 & 0.75 & & & & \\
\hline Total & 40 & & & 46 & & & \\
\hline
\end{tabular}

**High significance $P$-value. 
GENETIX version 4.0.2. software (Belkhir et al., 2000). The shared allele distance (DAS) has been calculated according to Chakraborty and Jin (1993) using POPULATION 1.2.28 Software (Langella, 2002). The derived distance matrix was used as input file for the Neighbour program (Felsenstein, 1995), to construct the Neighbour-joining (NJ) dendrogram visualized using TreeView software version 1.5 (Page, 1996).

\subsection{Cultivar identification key}

Cultivar's identification key was performed as reported by Saddoud et al. (2007). Genotypes were hierarchically organized according to the number of generated genotypes per locus, respectively recorded for Pom006, Pom013, Pom024, Pom014, Pom021, Pom010, Pom045, Pom055. Cultivars with common genotype were grouped together to fingerprint all tested one.

\section{Results}

\subsection{Polymorphism of microsatellites markers}

Among the 15 tested primer pairs, only 13 gave reproducible SSR patterns. A total of 40 microsatellites sized from 112 bp to 250 bp were scored using the 13 primer pairs (Table 2). Pom053 primer generates monomorphic patterns. The number of detected alleles per locus varied from 1 to 6 with an average of 3 alleles per locus. Pom021 locus has generated 6 alleles which only define 5 genotypes. The locus Pom006 is most informative since it generated the highest number of genotypes (7). The 13 selected primers gave polymorphic profiles representing a total of 46 genotypes (Table 2).

Our results show that some alleles have low frequencies, it is the case of the alleles 156 (Pom013) (0.02) and alleles 205 (Pom014), 198 (Pom021), 210 (Pom021) and 213 (Pom047) (Table 2). The highest allele frequency of 0.95 was recorded for allele 140 of Pom039 locus. As demonstrated by Fig. 1 the distribution of allelic frequencies at the 12 polymorphic loci indicated some differences between cultivars. The distributions of the detected alleles shows also a differentiation between the groups of pomegranates originating in the north and the south of Tunisia. Weak differences were observed between the two groups. In fact, 34 and 36 alleles were revealed for the south and the North group respectively and some specific alleles were identified. This is well explained in the case of Pom021 locus which exhibits 2 specific alleles of North group. Also, result shows five specific alleles of the North group not found in the remaining one. In addition, specific alleles were detected for GS1, ZH4, ZH5 and FP2 cultivars (Table 3). These cultivars are characterized by some specific morphological traits. GS1 produces a very acid juice. Cultivars ZH4 and ZH5 have coloured fruits and ZH5 gives a juice rich in polyphenolic contents. Cultivar FP2 is not fructiferous and has double varied flowers (Mars, 2001; Jbir et al., 2009).

The observed heterozygosity $\left(H_{\mathrm{obs}}\right)$ ranged from 0.05 for Pom039 to 0.97 for Pom047, with an average value of 0.39 . An important genetic diversity characterizes consequently the Tunisian pomegranate germplasm (Table 2).

Values of expected $\left(H_{\text {exp }}\right)$ and observed heterozygosities $\left(H_{\mathrm{obs}}\right)$ indicate that the SSR locus shows significant differences. Among the 13 SSR loci studied, only four loci (Pom021, Pom039, Pom047 and Pom055) illustrate no significant heterozygosity differences (Table 2). It is possible to advance the hypothesis that cultivar groups may belong to the same ancestral population relatively homogeneous. Intra-group and inter-group variability was estimated for each locus using Nei's parameters (Table 4). The multilocus values of $H_{s}$ and $H_{t}$ were 0.42 and 0.43 , respectively, suggesting that $88 \%$ of variability is revealed at the intra-group level. This assumption is confirmed by the low values of $G_{\text {st }}(0.01)$.

\subsection{Genetic distances and cultivar clustering}

To estimate the genetic diversity of $P$. granatum accessions from different regions, DAS genetic distances were calculated between cultivars. The minimum value of 0.03 was recorded between 'BY1' and 'CH9' and 'BY' 1 and 'CH8-2' cultivars, indicating a high genetic similarity. The maximum value (0.60) was observed between 'GS1' and 'TN9-2' suggesting the dissimilarities between these cultivars. The derived $\mathrm{NJ}$ dendrogram has clustered the 32 cultivars into three main groups (A, B and C) (Fig. 2).

The first marked group A classifies cultivars 'CH17', 'TN4', 'CH3' and 'JB4' together. The second group indicated B consists by 9 varieties with different denominations. Two cultivars 'ZH11' and 'ZH4' are strongly clustered, suggesting a high genetic similarity despite their phenotypic differences. All the remaining cultivars are clustered in the cluster $\mathrm{C}$. This group exhibited three sub-groups labelled C-1, C-2 and C-3. Despite their phenotypic divergences, the ornamental accessions 'FP1' and 'FP2' were grouped into cluster $(\mathrm{C})$ with the cultivated forms. It is worthy to note that cultivars with similar denominations are clustered into different tree branches. This is well illustrated in the case of 'Tounsi', 'Zehri' and 'Chelfi' varieties dispersed in the main groups A, B and C. Taking into account the geographical origin of the cultivars, we assume that a typical continuous genetic diversity characterizes the local pomegranate germplasm. This hypothesis is strongly supported since the cultivars studied are clustered independently from their geographical origin. The pattern of distribution of pomegranate genotypes by cluster analysis reveals the divergence of «Garsi 1» cultivar, characterised by distinct morphometric criteria. The fruits of (GS1) cultivar give a very acid juice. The topology of the obtained dendrogram shows that the classification of the Tunisian pomegranates which is done independently of their geographical origin and their denominations. Hence, despite the relative high degree of diversity, the Tunisian pomegranate germplasm represent a quite homogenous population. 
Locus Pom004

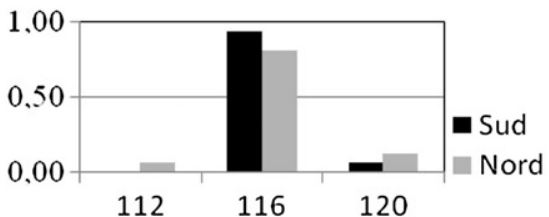

Locus Pom010

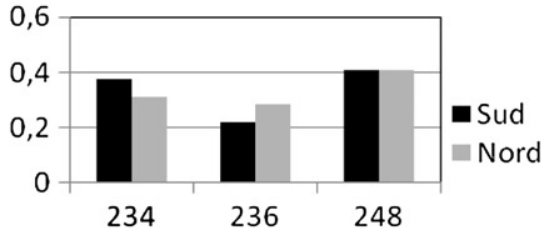

Locus Pom014

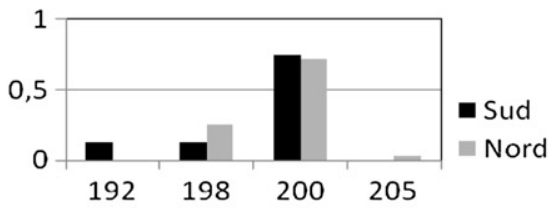

Locus Pom024

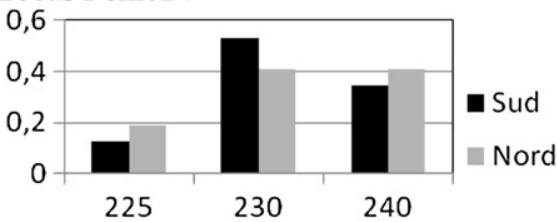

Locus Pom045

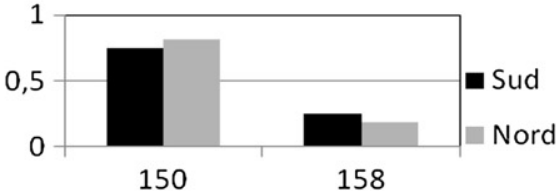

Locus Pom047

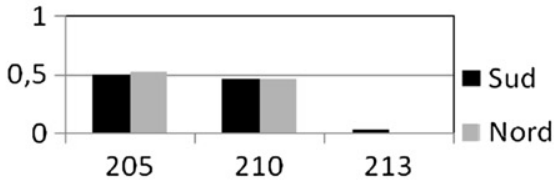

Locus Pom006

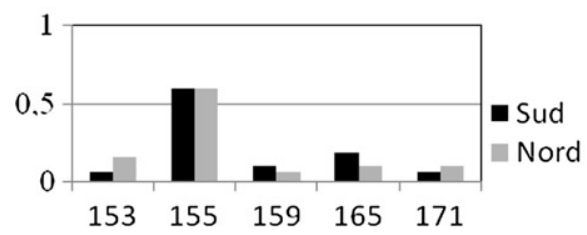

Locus Pom013

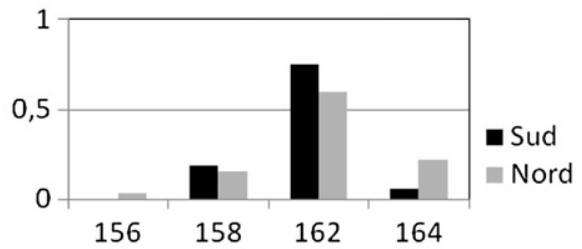

Locus Pom021

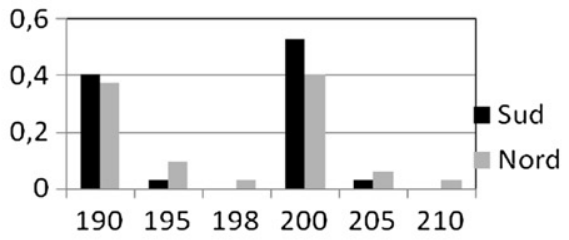

Locus Pom039

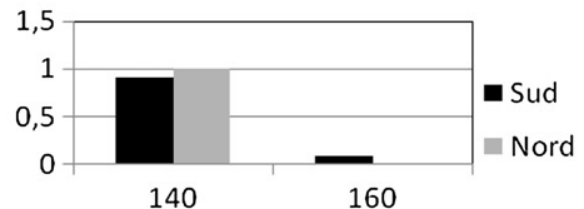

Locus Pom046

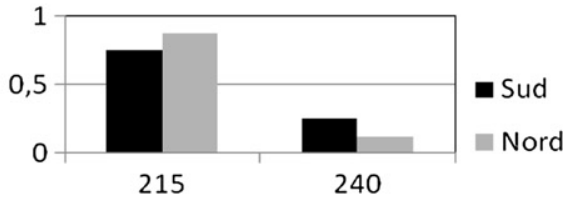

Locus Pom055

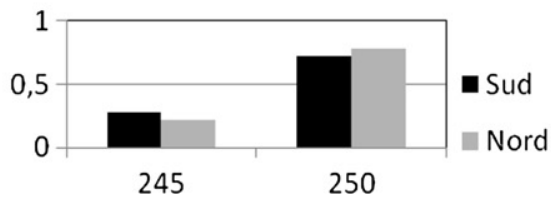

Fig. 1. Histograms illustrating the miocrosatellite alleles frequencies distribution in two groups of Tunisian pomegranate $\boldsymbol{\square}$ South group $\square$ North group.

\subsection{Cultivar identification key}

For each pomegranate cultivar, microsatellites loci Pom006, Pom013, Pom024, Pom014, Pom021, Pom010, Pom045, and Pom055 were scored and multilocus genotypes were established. A total of 29 alleles were identified for these loci. Among these, 8 loci only have permitted the genotyping of all studied cultivars (Fig. 3). In fact, the identified alleles have distinguished between 'BY1' 'CH9' and 'CH8-2' genotypes. Cultivars with the same denominations were unambiguously fingerprinted and discriminated; it's well explained in the case of 'ZH11' and 'ZH4' cultivars. Hypothesis of homonymy could be forward to explain this result. This identification key permitted the unambiguous discrimination of all studied accessions and confirmed the reliability of microsatellites markers for fingerprinting pomegranate genotypes. 
Table 3

Specifics alleles registered for some pomegranate cultivars from south and north groups.

\begin{tabular}{lll}
\hline Goups loci & South & North \\
\hline Pom013 & & FP2 (156) \\
Pom014 & & ZH4 $(205)$ \\
Pom021 & GS1 (213) & ZH5 (198, 210) \\
Pom047 & GS1 has the highest & FP2 is not fructiferous and has double flowers Variegated \\
Morphometric & juice titrable acidity. Cultivar & ZH4 and ZH5 cultivars have coloured fruit and ZH5 represent \\
& & the highest juice polyphenolic content. \\
\hline
\end{tabular}

\section{Discussion}

Our work demonstrate that the SSR primers designed for P. granatum by Hasnaoui et al. (2010) are able to generate very powerful markers to examine the molecular polymorphism of the local germplasm. Data exhibited evidence utility of this technology to fingerprint pomegranate cultivars. In fact, the number of generated SSR markers ( 40 alleles) scored in this study is higher than those reported for Iranian pomegranate cultivars using random amplified polymorphic DNA (RAPD) method (Talebi Baddaf et al., 2003; Sarkhosh et al., 2006). But it is lower when compared to that of AFLP markers reported in our previous study on Tunisian cultivars (Jbir et al., 2008). The targeted loci were characterized by a number of alleles per locus (an average of 3 ) relatively lower than those reported for other fruit species traditionally grown in Tunisia as Ficus carica L. (6.66 alleles/locus) (Saddoud et al., 2007) and Prunus armeniaca L. (4.4 alleles/locus) (Krichen et al., 2006). As described by Pirseyedi et al. (2010), the SSR markers revealed on Iranian pomegranate cultivars show an average of 2.9 alleles per locus and the observed and expected heterozygosities ranged from 0.15 to 0.87 and 0.29 to 0.65 , respectively (Pirseyedi et al., 2010). The presence of alleles with a low frequency in accessions of different origins suggests that the genetic variability is well dispersed across locations.

The comparison of the values obtained for the expected and observed heterozygotes indicates a heterozygote deficit and significant deviation from Hardy-Weinberg equilibrium for the majority of explored loci. It seems that the defined cultivar groups may belong to the same ancestral relatively homogenous population. A similar result was reported for Chinese pomegranate germplasm where the richness was supposed to be obtained by seedling propagation, natural and human selection (Yuan et al., 2007).

The multilocus values $H_{s}$ of $0.42, H_{t}$ of 0.43 and $G_{s t}$ of 0.01 suggested that $88 \%$ of variability is maintained at the intra-group level as concluded by several works conducted on Chinese germplasm based on AFLP marker (Yuan et al., 2007) and for other fruit species as date palm (Zehdi et al., 2004), olive (Ouazzani et al., 1995) and fig (Salhi-Hannachi et al., 2005).

The derived Neighbour-joining dendrogram proved that cultivars were clustered independently from their geographical origin and their denomination suggesting that a common genetic basis may characterize these cultivars despite their phenotypic divergences. This is strongly supported since the ornamental accession ('FP1' and 'FP2') did not significantly diverge from the cultivated forms. In addition, cultivars of similar denomination are clustered into different groups. This is well illustrated by the case of 'Chelfi' and 'Tounsi' cultivars that are dispersed in different clusters of the Neighbour-joining dendrogram. Mars and Marrakchi (1999) considered some local pomegranate cultivars such as 'Gabsi', 'Chelfi', 'Jebali', 'Zehri' as polyclonal varieties. These authors have reported that the phenotypic variation is highly influenced by the agroecosystems. Hypothesis of problems of synonymy and/or homonymy could be also forwarded to explain this result. While cultivars are locally denominated according to their origin and/or their fruit characteristics such as size, colour, juice, seed

Table 4

Total gene diversity $\left(H_{t}\right)$, mean gene diversity within population $\left(H_{s}\right)$ and genetic differentiation $\left(G_{\mathrm{st}}\right)$ among pomegranate cultivar groups.

\begin{tabular}{llll}
\hline Locus & $\mathrm{H}_{\mathrm{s}}$ & $\mathrm{H}_{\mathrm{t}}$ & $\mathrm{G}_{\text {st }}$ \\
\hline Pom004 & 0.22 & 0.22 & 0.02 \\
Pom006 & 0.59 & 0.60 & 0.01 \\
Pom010 & 0.65 & 0.66 & 0.01 \\
Pom013 & 0.49 & 0.50 & 0.02 \\
Pom014 & 0.41 & 0.42 & 0.01 \\
Pom021 & 0.62 & 0.63 & 0.01 \\
Pom024 & 0.61 & 0.62 & 0.01 \\
Pom039 & 0.08 & 0.09 & 0.04 \\
Pom045 & 0.34 & 0.35 & 0.01 \\
Pom046 & 0.30 & 0.31 & 0.02 \\
Pom047 & 0.51 & 0.51 & 0.01 \\
Pom053 & 0.00 & 0.00 & - \\
Pom055 & 0.37 & 0.38 & 0.01 \\
Multilocus & 0.42 & 0.43 & 0.01 \\
\hline
\end{tabular}




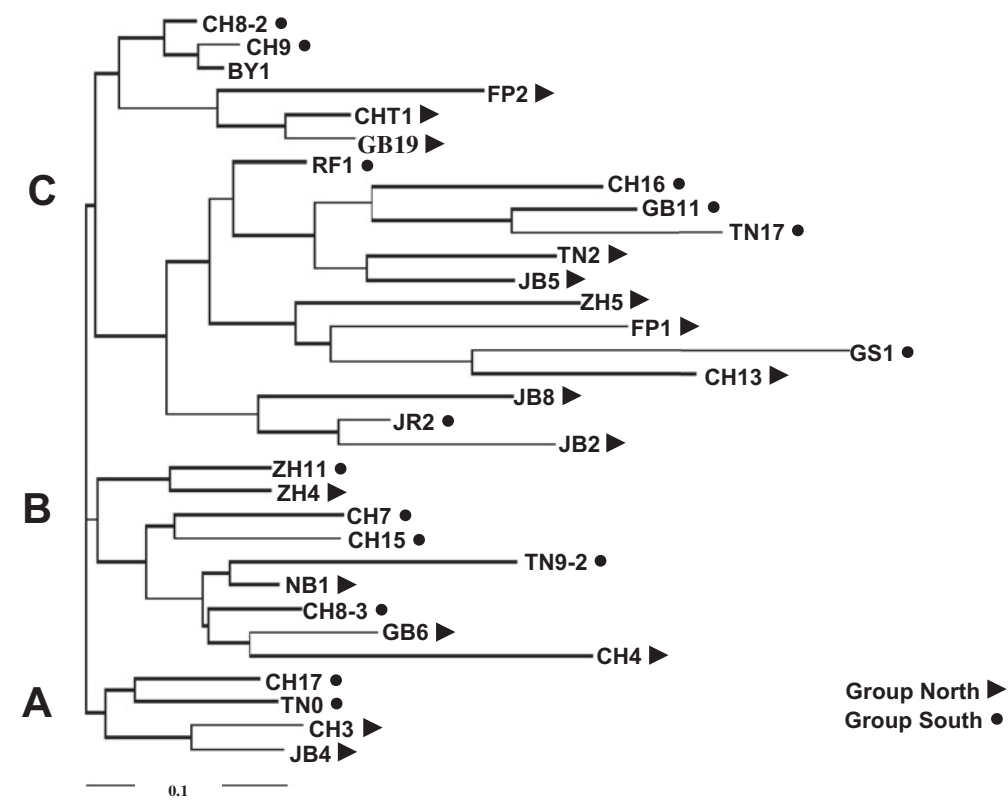

Fig. 2. Neighbour-joining dendrogram of 32 pomegranate accessions based on SSR markers and generated using «Das» genetic distances. Colours indicated groups of cultivars.

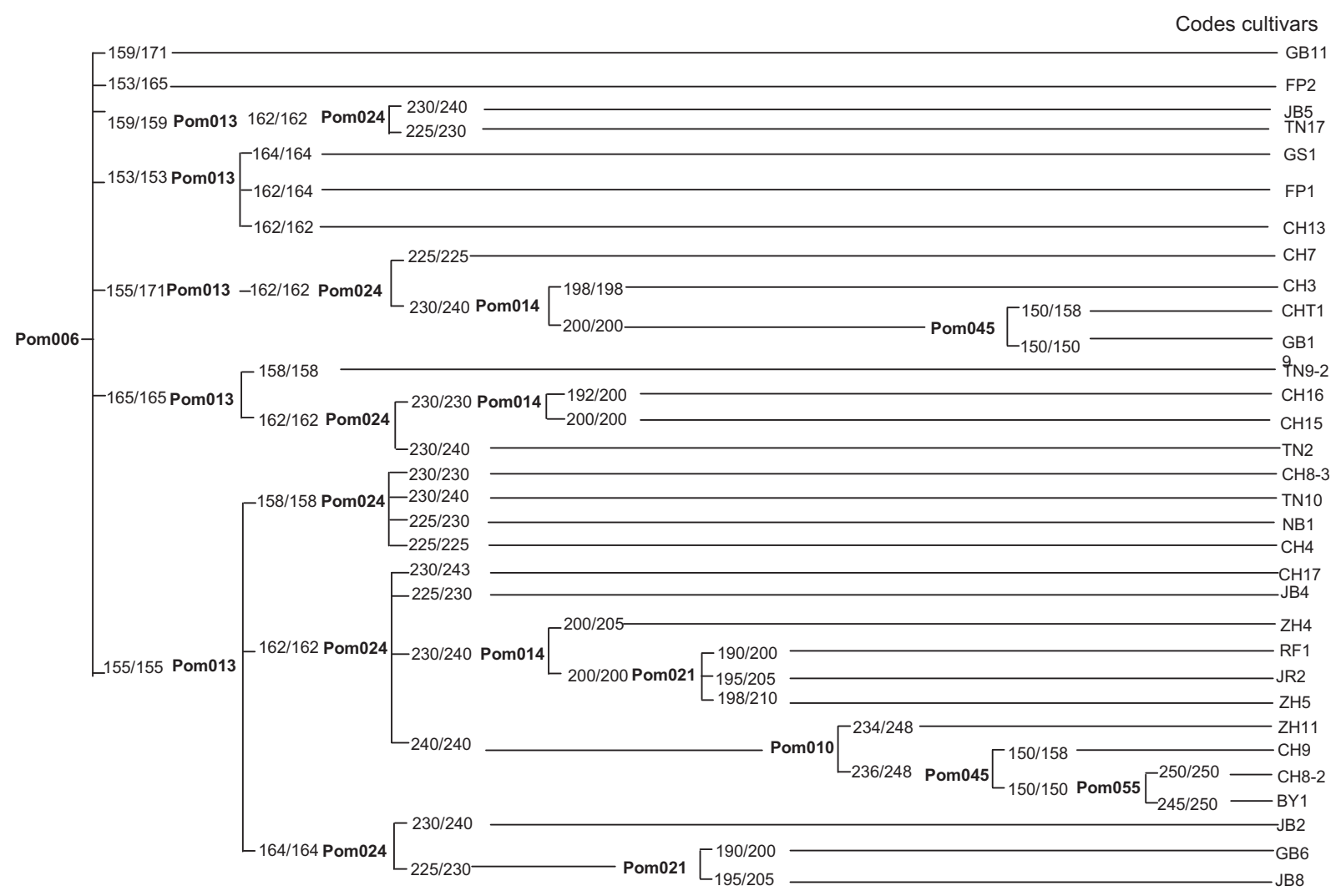

Fig. 3. Identification key of 32 Tunisian pomegranate genotypes based on 13 microsatellites loci fingerprints. Values writing in bold indicated SSRs loci. Normal writing values indicated allele's sizes. 
hardness, taste... (Mars and Marrakchi, 1998). Also in previous studies Jbir et al. (2008) have reported that cultivar clustering, based on AFLP makers, was no correlated with their geographic origin. This agrees with the result found for Chinese pomegranates where genetic distances between populations were not correlated to the geographical distance (Yuan et al., 2007). For wild and domestic Iranian pomegranate genotypes were divided into different clusters according to their geographical origins, in most cases, the clusters were not in agreement with the morphological traits as mentioned by Ebrahimi et al. (2010) (fruit colour, seed colour and taste). As far as we know, this is the first report on the development of an identification key that permitted the discrimination of all studied pomegranate cultivars using only 8 SSR loci. Our results confirm, once again, the reliability of microsatellites markers to fingerprint pomegranate genotypes as compared to other molecular markers as RAPD, ISSR and AFLP (Talebi Baddaf et al., 2003; Sarkhosh et al., 2006; Yuan et al., 2007; Jbir et al., 2008). A similar identification key was obtained by Zehdi et al. (2004) for 49 Tunisian date palm cultivars (Phoenix dactylifera L.) based on three microsatellite primers, revealing 25 alleles and 57 genotypes. Krichen et al. (2006) constructed for the Tunisian apricot landraces an identification key for 54 genotypes by the use of 26 Prunus microsatellite primers. With only five primers, it was possible to discriminate among all landraces studied, identifying 103 alleles and 155 different genotypes. In fig (F. carica L.), six SSR primers permitted to discriminate among 72 Tunisian local varieties with a resolving power of $97.2 \%$ (Saddoud et al., 2007; Baraket et al., 2010), the tested primers revealed 58 alleles and 124 genotypes. An identification key for 26 Tunisian olives (Olea europaea L.) was successful established for discriminating among local cultivars using three of ten SSR markers by Taamalli et al. (2008). Two microsatellite loci were sufficient to discriminate among all accessions studied and establish an identification key for 54 Tunisian almond cultivars (Gouta et al., 2012).

In summary, our result proved that the tested markers are a useful tool to evaluate genetic diversity and to identify relationships between pomegranate cultivars. In addition, the established identification key would be of great interest for establishing strategies and a rational management, improvement and selection programs in the local pomegranate germplasm facing climatic and environmental changes.

\section{Acknowledgements}

This work was supported by grants from the Tunisian "Ministère de l'Enseignement Supérieur et de la Recherche Scientifique et de la Technologie project Lab B02".

Dedicated to the Memory of Professor TRIFI Mokhtar, who passed away in September 2010.

\section{References}

Baraket, G., Chatti, K., Saddoud, O., Ben Abdelkarim, A., Mars, M., Trifi, M., Salhi Hannachi, A., 2010. Comparative assessment of SSR and AFLP markers for evaluation of genetic diversity and conservation of Fig, Ficus carica L., genetic resources in Tunisia. Plant Mol. Biol. Rep.. doi:10.1007/s11105-010-0217-X

Belkhir, K., Borsa, P., Goudet, J., Chikhi, L., Bonhomme, F., 2000. Genetix (Ver. 4.01), logiciel sous windows TM pour la génétique des populations. Laboratoire Génome et Population, Université Montpellier II, Montpellier, France.

Ben Nasr, C., Ayed, N., Metche, M., 1996. Quantitative determination of the polyphenolic content of pomegranate peel. Z. Lebensm. Unters. Forsch. A. 203 (4), 374-378.

Chakraborty, R., Jin, L., 1993. A unified approche to study hypervariable polymorphisms: statistical considerations of determining relatedness and population distances. In: Chakraborty, R., Epplen, J.T., Jeffreys, A.J. (Eds.), DNA Fingerprinting: State of the Science. Birkhäuser. Verlag, pp. $153-175$.

Dellaporta, S.L., Wood, J., Hicks, J.B., 1984. Maize DNA miniprep. Mol. Biol. Plants, 36-38.

Ebrahimi, S., Sayed-Tabatabaei, B.E., Sharifnabi, B., 2010. Microsatellite isolation and characterization in pomegranate (Punica granatum L.). Iranian J. Biotechnol. 8 (3), 156-163.

Felsenstein, J., 1995. PHYLIP (Phylogeny Interference Package) Version 3,5 c. Department of Genetics, University of Washington, Seattle, Washington.

Gouta, H., Ksia, E., Buhner-Zaharieva, T., Mliki, A., Gogorcena, Y., 2012. Development of an SSR-based identification key for Tunisian local almonds. Sci. Agric. 69 (2), 108-113.

Guarino, L., Miller, T., Baazara, M., Obadi, N., 1990. Socotra: the island of Bliss revisted. Diversity 6 (3-4), 28-31.

Hasnaoui, N., Buonamici, A., Sebastian, F., Mars, M., Trifi, M., Vendramin, G.G., 2010. Development and characterization of SSR markers for pomegranate (Punica granatum L.) using an enriched library. Conservation Genet. Resour. 2, 283-285.

Jbir, R., Hasnaoui, N., Mars, M., Marrakchi, M., Trifi, M., 2008. Characterization of Tunisian pomegranate (Punica granatum L.) cultivars using amplified fragment length polymorphism analysis. Sci. Hortic. 115, 231-237.

Jbir, R., Hasnaoui, N., Marrakchi, M., Trifi, M., Mars, M., 2009. Assessment of relationships in Tunisian pomegranate (Punica granarum L.) cultivars by pomological and AFLP markers. ISHS Acta Horticulturae 814: XII EUCARPIA Symposium on Fruit Breeding and Genetics.

Karale, A.R., Supe, V.S., Kaulgud, S.N., Kale, P.N., 1993. Pollination and fruit set studies in pomegranate. J. Maharashtra Universities 18 (3), 364-366.

Krichen, L., Mnejja, M., Arùs, P., Marrakchi, M., Trifi-Farah, N., 2006. Use of microsatellite polymorphisms to develop an identification key for Tunisian apricots. Genet. Res. Crop Evol. 53 (8), 1699-1706.

Langella, O., 2002. Populations (1. 2. 28 Software). CNRS, France. UPR9034.

Levin, G.M., 1995. Aspects of pomegranate culture in Turkmenistan. Plant Genet. Resour. News. 102, 29-31.

Mars, M., Carraut, A., Marrakchi, M., Gouiaa, M., Gaaliche, F., 1994. Ressources génétiques fruitières en Tunisie (poirier, oranger, figuier, grenadier). Plant Genet. Resour. News., 1-4.

Mars, M., 1996. Pomegranate genetic resources in the Mediterranean regions. In: Proceeding. First MESFIN Plant Genetic Resources Meeting, Tenerife, Spain, pp. 345-354.

Mars, M., Marrakchi, M., 1998. Conservation et valorisation des ressources génétiques du grenadier (Punica granatum L.) en Tunisie. Plant Genet. Resour. News. 114, 35-39.

Mars, M., Marrakchi, M., 1999. Diversity among pomegranate (Punica granatum L.) germplasm in Tunisia. Genet. Res. Crop Evol. 46, $461-467$.

Mars, M., 2001. Ressources génétiques du grenadier (Punica granatum L.) en Tunisie: prospection, conservation et analyse de la diversité. Thèse de Doctorat es Sciences Naturelles. Faculté des Sciences de Tunis, Université El Manar Tunis, Tunisie.

Mars, M., Marrakchi, M., 2004. Dynamique de floraison et régime de reproduction chez le grenadier (Punica granatum L.) en Tunisie. Fruits 59, 39-48. Melgarejo Moreno, P., Martínez Valero, R., 1992. El Granado. Mundi Prensa, Madrid, Spain.

Nei, M., 1978. Estimation of average heterozygosity and genetic distance from a small number of individuals. Genetics $89,583-590$. 
Ozguven, A.I., 1996. The genetic resources of pomegranate (Punica granatum) in Turkey. In: Proceeding First MESFIN Plant Genetic Resources Meeting. Tenerife, Spain, pp. 269-284.

Ouazzani, N., Lumaret, R., Villemar, P., 1995. Apport du polymorphisme alloenzymatique à l'identification variétale de l'olivier (Oleae europeae L.). Agronomie 15, 31-37.

Page, R.D.M., 1996. TREEVIEW: an application to display phylogenetic trees on personal computers. Comput. Appl. Biosci. 12, 357-358.

Pirseyedi, S.M., Valizadehghan, S., Mardi, M., Ghaffari, M.R., Mahmoodi, P., Zahravi, M., Zeinalabedini, M., Khayam Nekoui, S.M., 2010. Isolation and characterization of novel microsatellite markers in pomegranate (Punica granatum L.). Int. J. Mol. Sci. 11, $2010-2016$.

Saddoud, O., Chatti, k., Salhi-Hannachi, A., Mars, M., Rhouma, A., Marrakchi, M., Trifi, M., 2007. Genetic diversity of Tunisian figs (Ficus carica L.) as revealed by nuclear microsatellites. Hereditas 144, 149-157.

Salhi-Hannachi, A., Chatti, K., Mars, M., Marrakchi, M., Trifi, M., 2005. Comparative analysis of genetic diversity in two Tunisian collections of fig cultivars based on random amplified polymorphic DNA and inters simple sequence repeats fingerprints. Genet. Res. Crop Evol. 52, $563-573$.

Sambrook, J., Fritsch, E.F., Maniatis, T., 1989. Molecular Cloning: A Laboratory Manual. Cold Spring Harbor Laboratory Press, Cold Spring Harbor, NY, USA.

Sarkhosh, A., Zamani, Z., Fatahi, R., Ebadi, A., 2006. RAPD markers reveal polymorphism among some Iranian pomegranate (Punica granatum L.) genotypes. Sci. Hortic. 111, 24-29.

Talebi Baddaf, M., Sharifi Neia, B., Bahar, M., 2003. Analysis of genetic diversity in pomegranate cultivars of Iran, using random amplified polymorphic DNA (RAPD) markers. In: Proc. Third Natl. Congress Biotechnol, vol. 2, pp. 343-345.

Taamalli, W., Guena, F., Bassi, D., Daoud, D., Zarrouk, M., 2008. SSR marker based DNA fingerprinting of Tunisian olive (Olea europea L.) varieties. J. Agron. 7, $176-181$.

Yuan, Z., Yin, Y., Qu, J., Zhu, L., Li, Y., 2007. Population genetic diversity in Chinese pomegranate (Punica granatum L.) cultivars revealed by fluorescent-AFLP markers. J. Genet. Genomic 34 (12), 1061-1071.

Zehdi, S., Trifi, M., Billotte, N., Marrakchi, M., Pintaud, J.K., 2004. Genetic diversity of Tunisian date palms (Phoenix dactylifera L.) revealed by nuclear microsatellite polymorphism. Hereditas 141, 278-287. 